\title{
The difference between alternative and conventional medicine
}

\section{Opinion}

The difference between alternative and conventional medicine is the dominant spiritual dimension. Recall also that the treatment of the body against a background of soulless consciousness should be referred to veterinary medicine." From the report of the international commission under the auspices of the International Ortega Foundation.

When I received a letter with a proposal to write an article in your magazine, I had two different thoughts. On one hand, I thought it would be interesting, but on the other hand, I understood the responsibility I would have to convey the readers about a topic what is considered new and unknown for many of them. After all, I decided to talk about what I had seen; the problems and the causes that led to the patients come to me.

My point of view does not coincide with the point of view of official medicine, but it has a right to be because the number of people who have gone from me cured and happy, thanked me and said they would pray for me. I'm talking about more than six thousand people (in Nicaragua only). That says about my rightness in a cure of disease, and I have to say that only very serious cases come to me. Many of them have visited various doctors for decades, but they could not get relief either getting rid of their diseases. Those who were told that the medicine is powerless, come to me with no diagnosed diseases. I got even those who were told according to the statements of the doctors, have remaining to live a couple of weeks.

What, in my opinion, is the cause of various diseases? This is in addition to the physical manifestations in the form of tumors, inflammations, hernias, etc., and even mental reasons: different offenses, quarrels, hatred, jealousy, unhappy life, etc. When a person lives in harmony and enjoying life, the disease does not occur. For example, a New York woman came to me once. She had a problem with her knee, she couldn't walk. At first, I put away the pain. Then, the knee cures itself, but I wasn 't able to help without asking her what is happening in the relationship with her husband, because I saw that it all started with that. At the beginning, she was amazed to see that I knew it. Then, after I describe her not only how it looks, but also where she lives at, her home, she was amazed. The patient began to trust me completely, and said that she lived in a house that they had bought together with her ex-husband. He has already left her for another woman several years ago, and she does not know how many more could live in this house. After all, he may at any time require its part of the house. That idea wasn't leaving her, she was always thinking about it, but wasn't decided to find it out. I told her that it was she needed to treat the knee and at the same time she needed to solve the problem with the house, because that would not let her rest.

Under my pressure, she went to her ex-husband, and everything was resolved safely. He asked her to give him a small part of the cost of the house, because they have a common child. She was happy, thanking me. The problem has been removed, respectively, and then the disease has been completely cured.

\author{
Volume II Issue 3 - 2018 \\ Larisa Maksimadzhi \\ Bio Energy Medical Center, Nicaragua
}

Correspondence: Larisa Maksimadzh, Bio Energy Medical Center, Nicaragua, Tel 5052265 7598, 5058835 7777, Email rechka2006@mail.ru

Received: January 28, 2018 | Published: May 16, 2018

Therefore, I want to reiterate that when harmony is disturbed, then there's some resentment, such as the husband does not understand the wife; the wife and husband cannot find a common language, a son or daughter do not like me, anger and disgust for the one who did it, etc... All of these reasons initially leads to the emergence of diseases and then, manifest in the form of a mental disease to get after all, a physical form.

When somebody comes to me, I see on that patient some kind of issues like hernia, interlacing muscles, etc. I also see a problem of spiritual, mental order, which should also be resolved to ensure that the disease won't ever come back. I would say that the disease of wrong thoughts needs to be cured.

I see live people, who come to me looking for a cure of their disease, but I also see dead people, who often come to stay with their relatives during my sessions. For example, a family with a child came to me for treatment when I was invited to Mexico to cure a patient. All of them, they said, were good, but they were constantly sick and did not see the causes. When I told them that their grandmother just came to me, they did not believe me. But after I told them that she was complaining that she felt her shoulders uncomfortable, her daughter began to cry and said that her mother was a very fat woman, and they could not find the desired size of the coffin, so they had to literally squeeze the dead woman in it.

After the session they went to the church and fulfill all that I recommended them. By the end of my stay in Mexico, the whole family was in good health.

Deaths continue to live, but in another dimension, and if they show themselves to others, is to give us an advice, correct something, etc. They come to me and their relatives and friends begin to live in harmony with the world, let's say, with the whole universe. Whenever I'm working with somebody, some situations that needed to be corrected flashes. I can give infinite examples about that. I would add that this is a such a gift that I have and I'm grateful for it, respecting and thanking the person who gave it to me. People with such a gift are definitely there, but there are a few and I had never meet them in my life. I hadn't meet them at the internet either, because they can come to me from any source. I see that it is necessary to treat and know why this occurs. I like to enter into the patient and felt his problems as well as where the pain is and when it happens. I feel more 
vibration, see punctured cells. All the patients who came to me to the center of bioenergetics medicine were cured, despite the fact that the diseases are various and different. There is a cure for the effects of brain surgery, heart disease, back problems, urine, gallstone disease, arthritis, neuro-dermatitis, varicose veins, asthma, multiple sclerosis, etc. Diseases are too many to enumerate them all.

\section{Acknowledgements}

None

\section{Conflict of interest}

Author declare there is no conflict of interest 